Article

\title{
Living at the Water's Edge: A World-Wide Econometric Panel Estimation of Arable Water Footprint Drivers
}

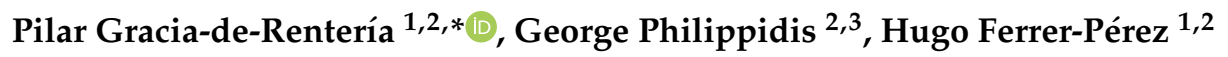 \\ and Ana Isabel Sanjuán 1,2 \\ 1 Department of Agrifood and Natural Resource Economics, Agrifood Research and Technology Centre of \\ Aragon (CITA). Avda. Montañana, 930, 50059 Zaragoza, Spain; hferrer@cita-aragon.es (H.F.-P.); \\ aisanjuan@aragon.es (A.I.S.) \\ 2 AgriFood Institute of Aragon-IA2 (CITA-University of Zaragoza), 50013 Zaragoza, Spain \\ 3 Aragonese Agency for Research and Development (ARAID), Agrifood Research and Technology Centre of \\ Aragon (CITA). Avda. Montañana, 930, 50059 Zaragoza, Spain; gphilippidis@aragon.es \\ * Correspondence: mpgracia@cita-aragon.es; Tel.: +34-976-716356
}

Received: 18 March 2020; Accepted: 4 April 2020; Published: 8 April 2020

\begin{abstract}
As part of the Sustainable Development Goal (SDG) for ensuring clean water and sanitation worldwide by 2030, SDG target 6.4 seeks to attain sustainable withdrawals of freshwater through efficiency gains with a view to relieving water stress in vulnerable populated areas. The water footprint (WF) is a key metric to measure this concept, although the dynamics of the drivers of the WF through space and time remain relatively under-researched, whilst in foresight studies, the WF is often subject to simplistic assumptions. Thus, constructing a panel dataset of 130 countries and 156 crops for the period 2002-2016, this paper empirically assesses the sign and magnitude of WF drivers of agricultural crop activities, employing a careful selection of demographic, economic and climatic drivers. The study uncovers evidence of significant deviations in WF drivers across regions segmented by relative wealth, relating specifically to the stage of economic development and the presence (absence) of economies of scale, whilst we confirm that geographical coordinates have a major bearing on the climatic WF driver. Moreover, examining the temporal dimension, there is compelling evidence supporting a structural break in the role that technical progress exerted on the WF prior to, and in the wake of, the 2008 financial crisis.
\end{abstract}

Keywords: water footprint; drivers; agriculture; global coverage; panel data

\section{Introduction}

Population growth, accompanied by rapid economic and social transition are pushing mankind beyond the planet's biophysical limits, resulting in climate change, ecosystem degradation and unsustainable resource depletion. In a bid to support progress toward a more globally sustainable model of human development over the 2015-2030 period, the Sustainable Development Goals (SDGs) [1], fronted by the United Nations (UN), present a coherent monitoring system of metrics with, in some cases, clearly delineated targets [2].

In the case of freshwater, this finite resource constitutes a fundamental element of human existence with competing needs across domestic, economic and environmental uses. Within the SDG framework, goal 6.4 explicitly states the need to, "by 2030, substantially increase water-use efficiency across all sectors and ensure sustainable withdrawals and supply of freshwater to address water scarcity and substantially reduce the number of people suffering from water scarcity" [2]. Unfortunately, as anthropological interference with the earth's water cycle gathers pace, the proportion of populated 
areas worldwide undergoing water stress could rise, with detrimental impacts to human health, rising poverty, social inequalities and localised conflicts over scarce resources [3].

As a metric to understand the efficiency of water usage, the water footprint (WF) has garnered considerable interest amongst policy makers. The term, originally coined by Hoekstra [4], refers to the direct and indirect usage of water within a production process and reflects the cumulative consumption of said resource through the entire supply chain. Moreover, unlike the traditional approach regarding blue water withdrawal, the WF concept explicitly distinguishes between green, blue and grey footprints. The blue WF refers to the consumption of surface and groundwater resources, the green WF refers to the consumptive use of rainwater stored in the soil, and the grey WF refers to water contaminations and is measured as the volume of freshwater required to assimilate water pollutants [5].

Interest in this intensity measure of water usage has contributed to a growing body of empirical academic literature. A number of studies analyse the drivers of water use, e.g., [6], and virtual water trade, e.g., [7-11]. Another strand of the literature examines climate change and its concomitant impact on water scarcity, e.g., [12,13], or the repercussions of changing diets in relieving water resource pressures, e.g., [14-16]. Further afield, other 'foresight' studies focus on establishing medium- to long-run water use projections under alternative socio-economic transition pathways, e.g., [13,17,18].

In this latter group of studies, a common denominator is the assumption that, over time, the WF remains constant or only varies at an assumed rate. Moreover, there is a dearth of literature that evaluates the drivers of the WF. Although some papers have analysed the factors that influence water productivity, among others [19-22], their approaches are varied and they concentrate on blue water withdrawal rather than on the WF concept. Moreover, most of these papers neglect socioeconomic drivers $[23,24]$ and focus only on the hydrological drivers for some specific crops and locations. Accordingly, there is a paucity of relevant literature with global spatial coverage, whilst changing WFs over time is an area which has received relatively scant attention $[20,25]$.

To fill this gap in the literature, the current study aimed at assessing the sign and magnitude of a series of macroeconomic, climatic and structural input drivers on the agricultural crop WF over space and time, based on a constructed panel data set of water usage for 130 countries. With $70 \%$ of the world's freshwater resources being used in agriculture [3], the focus of the paper is restricted to this collective of activities. The results of the paper reveal statistically significant drivers of crop water intensity related to the pattern of input usage, whilst there is evidence that the WF is strongly linked to the level of macroeconomic development and economies of scale. Examining the temporal dimension of the study more closely, the results suggest that the reduced arable WF trends that were observed up to 2007 are, in developed regions, subsequently reversed in the wake of the global market shock arising from the 2008 crisis. Comparing by geographical areas, there is a heterogeneous effect across the economic development and temperature growth drivers of the $\mathrm{WF}$, which seems to be influenced by the income level of each region and by the latitude in which it is located, respectively.

The remaining sections of the paper are structured as follows. Section 2 discusses the construction of the panel dataset and its descriptive characteristics. Section 3 explains the methodology and Section 4 presents and discusses the results. A final section concludes.

\section{Data}

To assess the quantity of water needed to produce crop products, we employed and adapted the database developed by Mekonnen and Hoekstra [26]. This database provides blue, green and grey WF in $\mathrm{m}^{3}$ of water per ton of production, for a number of specific products and countries, averaged over the period 1996-2005. The WF, defined as the ratio between evapotranspiration (in $\mathrm{m}^{3}$ per hectare) and crop yield (in ton per hectare), is expected to change over time, and, as such, was modified to be time-variant. To perform this task, an approach validated by Tuninetti et al. [27] and adopted by other relevant studies, e.g., $[6,10,11,28]$, was applied. This approach assumes that evapotranspiration 
remains stable over time and WF changes are only driven by yield variations, so yearly country-specific WFs for each product can be obtained as

$$
W F_{p, c, t}=W F_{p, c} \frac{Y_{p, c}}{Y_{p, c, t}}
$$

where subscripts $\mathrm{p}, \mathrm{c}$, and $\mathrm{t}$ refer to the product, country, and year considered, respectively; $\mathrm{WF}_{\mathrm{p}, \mathrm{c}, \mathrm{t}}$ is the annual crop WF for the period of analysis $t=2002, \ldots, 2016$ (due to information constraints, this study is limited to the period 2002-2016, since no WF driver information is available for the period 1996-2001); $W_{p, c}$ is the average 1996-2005 WF from Mekonnen and Hoekstra [26]; $Y_{p, c}$ is the average 1996-2005 crop yield; and $Y_{p, c, t}$ is the annual crop yield for $t=2002, \ldots, 2016$. Yield data were obtained from Food and Agriculture Organization (FAO) [29].

With these data, the resulting green and blue WFs in $\mathrm{m}^{3}$ of water per dollar of production value were also calculated. To do so, the annual WFs obtained as $W_{\mathrm{p}, c, t}$ in (1) were multiplied by the annual production quantity of each product (in tons) and divided by its production value (in constant US \$), employing data from FAO [29]. This transformation allows one to evaluate the WF, taking into account the value added generated by water use, and serves as a basis for assessing water use predictions and virtual water flows that are generally expressed in monetary terms.

Employing this process, one obtains the annual green and blue WFs (in $\mathrm{m}^{3}$ of water per tonne, and in $\mathrm{m}^{3}$ of water per dollar of production) for each product in each country for the period $t=2002, \ldots, 2016$. As a result, a panel dataset is generated for this period for 130 countries and 156 crop products (due to information constraints, the WF in $\mathrm{m}^{3}$ per dollar can only be analysed for 117 countries and 153 products), as well as for the aggregate agricultural crop sector of each country. Table 1 presents the representativeness of the sample of 130 countries in terms of regional and income dispersion according to the number of countries and the population, following the World Bank's classification.

Table 1. Representativeness of the sample.

\begin{tabular}{|c|c|c|c|c|}
\hline \multirow[b]{2}{*}{ Regions } & \multicolumn{2}{|c|}{ Sample } & \multicolumn{2}{|c|}{ World } \\
\hline & $\begin{array}{c}\% \text { of } \\
\text { Countries in Each } \\
\text { Region }\end{array}$ & $\begin{array}{c}\% \text { of } \\
\text { Population in } \\
\text { Each Region }\end{array}$ & $\begin{array}{c}\% \text { of } \\
\text { Countries in Each } \\
\text { Region }\end{array}$ & $\begin{array}{c}\% \text { of } \\
\text { Population in } \\
\text { Each Region }\end{array}$ \\
\hline \multicolumn{5}{|l|}{ Per geographical region: } \\
\hline East Asia and Pacific (EAP) & $11 \%$ & $16 \%$ & $13 \%$ & $32 \%$ \\
\hline Europe and Central Asia (ECA) & $35 \%$ & $17 \%$ & $33 \%$ & $13 \%$ \\
\hline Latin America and Caribbean (LAC) & $18 \%$ & $11 \%$ & $17 \%$ & $9 \%$ \\
\hline Middle East and North Africa (MENA) & $8 \%$ & $6 \%$ & $10 \%$ & $5 \%$ \\
\hline North America (NA) & $1 \%$ & $6 \%$ & $2 \%$ & $5 \%$ \\
\hline South Asia (SA) & $4 \%$ & $32 \%$ & $4 \%$ & $24 \%$ \\
\hline Sub-Saharan Africa (SSA) & $23 \%$ & $12 \%$ & $21 \%$ & $12 \%$ \\
\hline \multicolumn{5}{|l|}{ Per income group: } \\
\hline Low income (LI) & $14 \%$ & $6 \%$ & $13 \%$ & $8 \%$ \\
\hline Middle income (MI) & $54 \%$ & $72 \%$ & $53 \%$ & $76 \%$ \\
\hline High income (HI) & $32 \%$ & $22 \%$ & $34 \%$ & $16 \%$ \\
\hline
\end{tabular}

Figure 1 shows the evolution of global crop (blue and green) water use and the respective footprint, and compares these magnitudes with the evolution of Gross Domestic Product (GDP) per capita. The progressive increase in GDP per capita during the period considered $(+32.08 \%)$ coincided with an increase in crop water use $(+20.38 \%)$. However, this increase in the use of water contrasts with the reduction in the arable WF $(-10.67 \%)$, suggesting a positive relationship between worldwide economic progress and water productivity. Figure 2 presents regional dispersion of crop (blue and green) water use and footprint. Arable water use disparities appear to be close related with the crop production level of each country, but the geographical pattern of the WF does not seem so obvious. These facts highlight the importance of a statistical analysis of the factors driving the WF variations over time and space. Note that the WFs presented in these figures are only expressed in $\mathrm{m}^{3} / \$$, but the magnitudes in $\mathrm{m}^{3} /$ tonne (which are not presented for brevity) exhibit similar behaviour. 


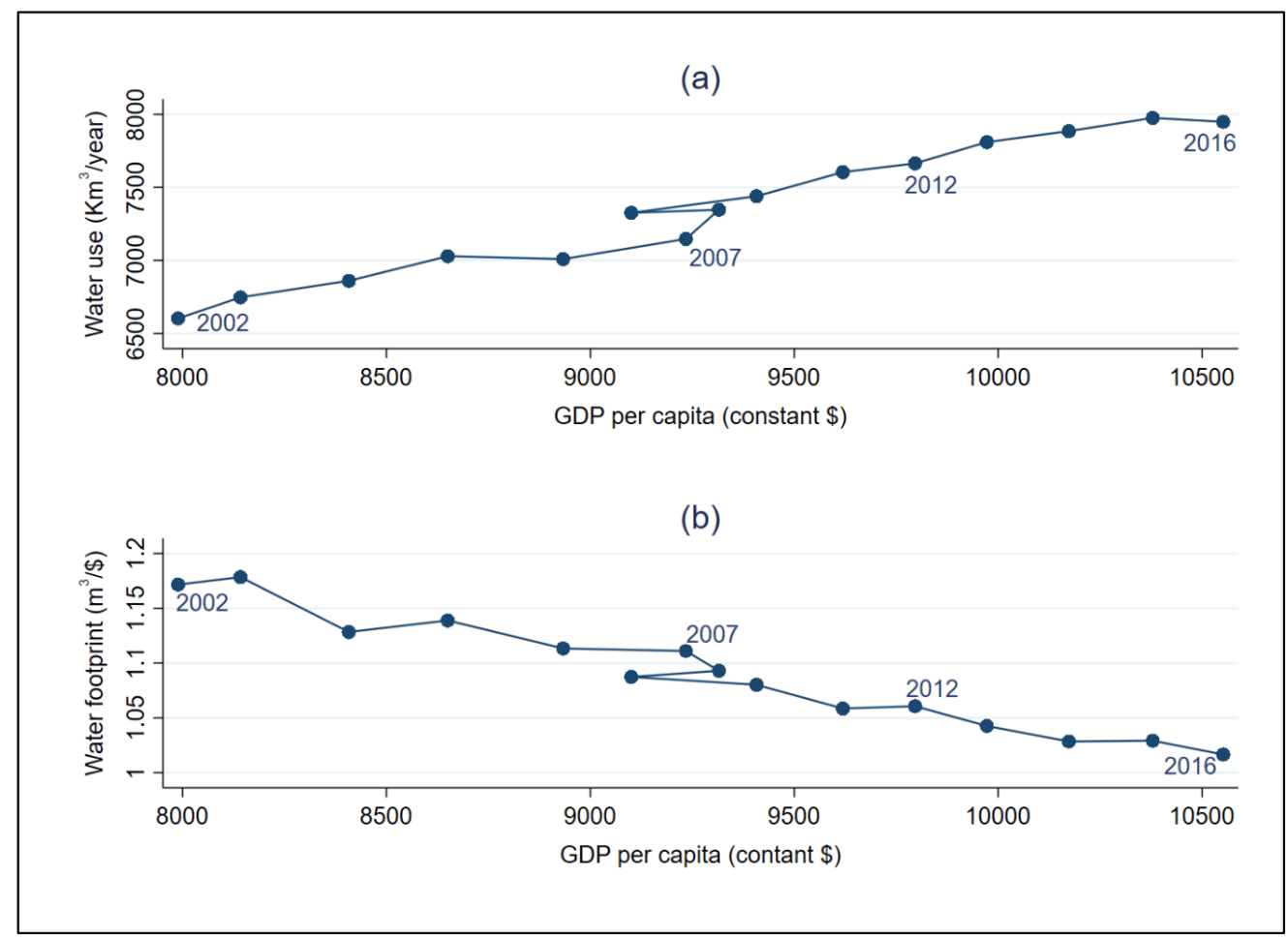

Figure 1. (a) Evolution of global arable water use vs. GDP per capita; (b) Evolution of global arable WF vs. GDP per capita. Each point in the figure represents, for each year, the combination of GDP per capita and water use or WF at worldwide level. Water use and WF are expressed as the sum of the blue and green component. Data presented in the figure represent only the crop products and countries covered by this study, so these data may change slightly when considering additional crops and/or countries.

The WF drivers considered in this study were selected in reference to the aforementioned approach validated by Tuninetti et al. [27] that demonstrates that WFs are mainly driven by yield changes, accordingly also with the evidence of $[10,30]$. The selection was based on a detailed review of the aforementioned literature in the introduction section, trying to comprise the demand and supply forces that may influence crop yield and, subsequently, WFs. Demand forces are proxied by GDP per capita and population levels, while supply conditions are characterised through the application of key structural inputs in agricultural cropping activities, in this case, capital, labour and fertilisers. Moreover, a climatic variable (temperature change) is introduced as a factor that may influence both crop yield and evapotranspiration and, therefore, WFs.

GDP per capita (in constant US \$) and population (persons) data for each country were extracted from the World Bank [31]. Input usage was measured through its yield, both in quantity and monetary terms. That is, input yields were gauged in terms of the quantity (or value) of production (in tonnes and constant $\$$, respectively) per unit of capital, labour and fertiliser. Specifically, these inputs were specified as the fixed capital formation cost (in constant US \$), the number of employees (persons) and the quantity of fertilisers used (in kilograms), respectively. The quantity and value of the production data by country and crop product come from FAO [29] and data on the use of inputs by country come from the World Bank [31]. To obtain the use of inputs by country and product, the average country use of inputs per hectare was calculated and this ratio was multiplied by the arable land area dedicated to each product, where land area information was obtained from the FAO [29]. Finally, temperature change for each country is extracted from FAO [29] and measured as the variation (in ${ }^{\circ} \mathrm{C}$ ) with respect to the baseline period 1951-1980. 


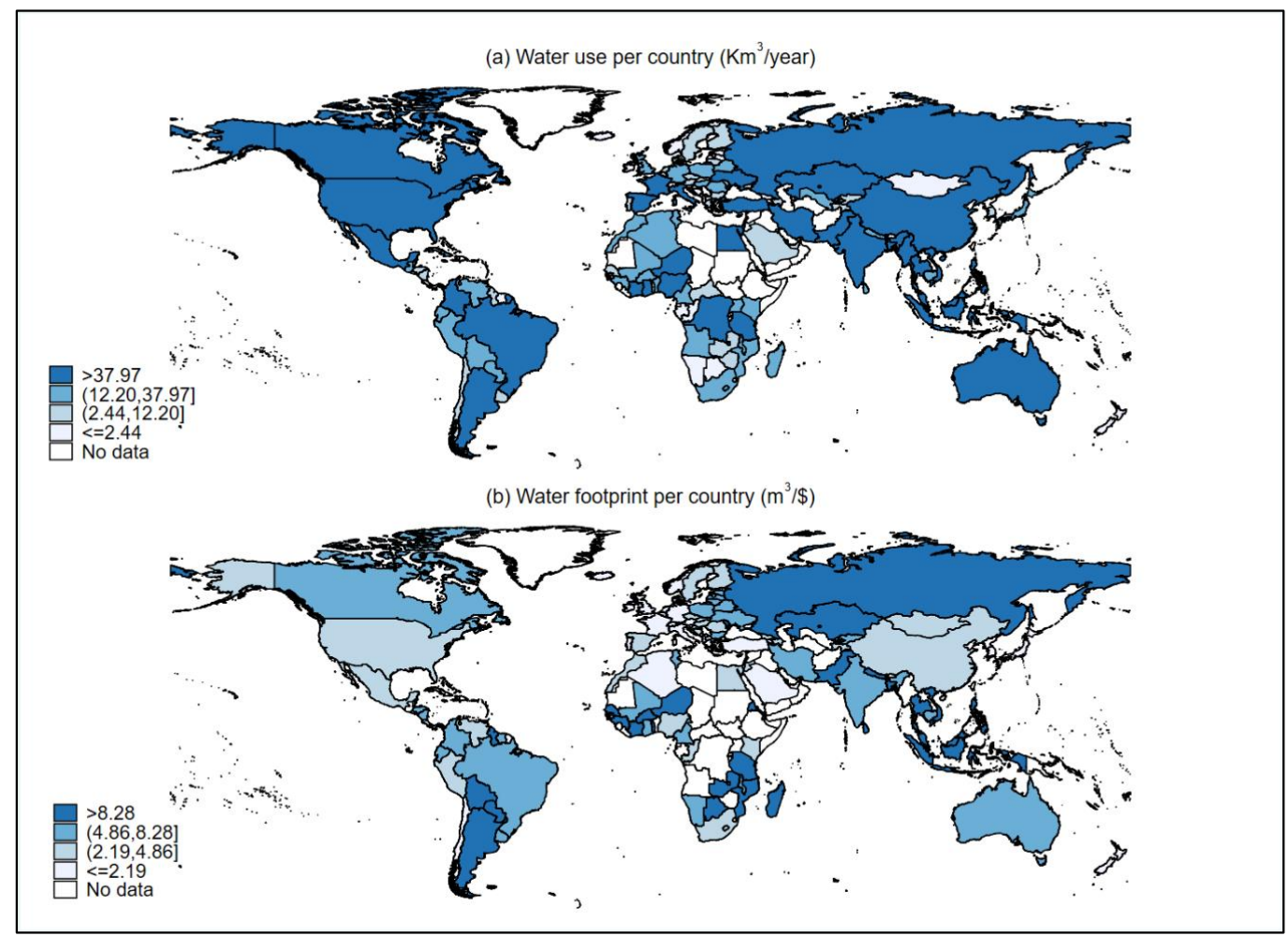

Figure 2. (a) Arable water use per country; (b) Arable water footprint (WF) per country. Country data reflect the average magnitude for the period 2002-2016. Water use and WF are expressed as the sum of the blue and green component. Data presented in the figure represent only the crop products covered by this study, so these data may slightly change when considering additional crops. Missing data in Panel B but not in Panel A are due to different coverage of the database when variables are expressed in quantity and monetary terms (130 and 117 countries, respectively). Source: Own elaboration based on Makonnen and Hoekstra [26]; basemap from Natural Earth.

\section{Model Specification and Selection}

This section presents the methodology used to assess the drivers of arable WFs based on the aforementioned data from Mekonnen and Hoekstra [26] and on the determinants' specification detailed in the previous section. Among the possible model specifications to represent this relationship, the double-logarithmic model was selected, which is typically used in the related literature, e.g., [21,32]. The log-log specification, which represents a linearization of the common Cobb-Douglas function, permits non-linear relationships amongst the original variables.

Our data estimation requires the use of panel techniques, leading to the following model specification

$$
\begin{gathered}
\ln \mathrm{WF}_{\mathrm{it}}=\alpha+\beta_{1} \ln \mathrm{GDPPc}_{\mathrm{it}}+\beta_{2} \ln \mathrm{POP}_{\mathrm{it}}+\beta_{3} \ln \mathrm{KYIELD}_{\mathrm{it}}+\beta_{4} \ln \mathrm{LYIELD}_{\mathrm{it}}+ \\
\beta_{5} \ln \mathrm{FYIELD}_{\mathrm{it}}+\beta_{6} \ln \mathrm{TEMP}_{\mathrm{it}}+\mathrm{u}_{\mathrm{it}},
\end{gathered}
$$

where $i$ refers to the panel variable and $t=2002, \ldots, 2016$; WF is the water footprint, GDP pc is the GDP per capita, POP is population, KYIELD, LYIELD, and FYIELD are the capital, labour, and fertiliser yield, respectively, TEMP is the temperature variation, and $u$ is the error term assumed to be identically and independently distributed.

As mentioned in the previous section, these variables were obtained for different levels of disaggregation and different measurement units, resulting in the estimation of four model specifications of Equation (2). In the first model (M1), the WF is expressed in $\mathrm{m}^{3} /$ tonne and input yield in tonne/input unit, and the aggregate agricultural crop sector is analysed so that, in Equation (2), i refers to each 
country. In the second model (M2), the same variable specification was used but with a greater sectoral disaggregation, so i refers to each crop product in each country. Accordingly, the resulting coefficients measure the relation along time after controlling for country and product heterogeneity with panel fixed effects. Models 3 (M3) and 4 (M4) are equivalent to M1 and M2, but the WF is expressed in $\mathrm{m}^{3} / \$$ and input yield as $\$$ /input unit. These two alternative specifications allow one to ensure the robustness of the estimates expressed in both quantities and values.

The results of the four estimated panel models with fixed effects are shown in Table 2. Given the logarithmic representation of the model variables, estimated coefficients may be interpreted as elasticities. Note also that a time trend was included to account for an evolution of WF beyond that explained by the set of determinants contemplated. In this sense, the trend can be viewed as a proxy for technological change. Furthermore, year dummies are also included to capture the possible influence of common factors across the countries/crops omitted in the specification. The last four rows of the table report, respectively, the number of observations and the number of groups used in each model, the usual measure of goodness of fit, $\mathrm{R}^{2}$, and the RESET test, to ensure correct model specification. Moreover, the usual panel unit root tests have been used to check the stationarity of the variables involved, confirming the correct estimation of the models in levels (results of these tests are not reported for brevity, but are available on request).

Table 2. Estimation results.

\begin{tabular}{ccccc}
\hline Variables & M1 & M2 & M3 & M4 \\
\hline Constant & $19.237^{* * *}$ & $26.108^{* * *}$ & $15.851^{* * *}$ & $24.402^{* * *}$ \\
& $(2.1798)$ & $(0.4781)$ & $(2.2708)$ & $(0.5029)$ \\
Trend & $0.005^{* *}$ & $0.012^{* * *}$ & 0.004 & $0.012^{* * *}$ \\
& $(0.0021)$ & $(0.0004)$ & $(0.0024)$ & $(0.0004)$ \\
ln GDPpc & $-0.263^{* * *}$ & $-0.357^{* * *}$ & $-0.310^{* * *}$ & $-0.420^{* * *}$ \\
& $(0.0795)$ & $(0.0195)$ & $(0.1005)$ & $(0.0221)$ \\
ln POP & $-0.658^{* * *}$ & $-1.065^{* * *}$ & $-0.629^{* * *}$ & $-1.003^{* * *}$ \\
& $(0.1342)$ & $(0.0290)$ & $(0.1318)$ & $(0.0281)$ \\
ln KYIELD & $-0.126^{* * *}$ & $-0.314^{* * *}$ & $-0.164^{* * *}$ & $-0.345^{* * *}$ \\
& $(0.0300)$ & $(0.0081)$ & $(0.0366)$ & $(0.0092)$ \\
ln LYIELD & $-0.161^{* * *}$ & $-0.397^{* * * *}$ & $-0.211^{* * *}$ & $-0.403^{* * *}$ \\
& $(0.0513)$ & $(0.0100)$ & $(0.0529)$ & $(0.0111)$ \\
ln FYIELD & $-0.028^{* * *}$ & $-0.069^{* * *}$ & $-0.023^{* * *}$ & $-0.072^{* * *}$ \\
& $(0.0101)$ & $(0.0031)$ & $(0.0091)$ & $(0.0038)$ \\
ln TEMP & -0.001 & $-0.018^{* * *}$ & -0.005 & $-0.016^{* * *}$ \\
& $(0.0050)$ & $(0.0009)$ & $(0.0061)$ & $(0.0008)$ \\
Time fixed effects & YES & YES & YES & YES \\
\hline No. Observations & 1732 & 92,365 & 1602 & 80,976 \\
No. Groups & 130 & 6788 & 117 & 5791 \\
\hline R-squared & 0.38 & 0.79 & 0.50 & 0.83 \\
$p$-value of Reset test & 0.04 & 0.04 & 0.18 & 0.21 \\
\hline
\end{tabular}

Note: robust standard errors in parentheses. ${ }^{* * *} p<0.01,{ }^{* *} p<0.05$. GDPpc refers to Gross Domestic Product per capita; POP is population; TEMP refers to the temperature change; and KYIELD, LYIELD and FYIELD is the capital, labour and fertilizer yield, respectively.

Model 4, with its higher degree of sectoral disaggregation and with the variables expressed in monetary terms, outperforms the rest of the models: it does not fail to pass the RESET test and reports the highest $\mathrm{R}^{2}$. On the strength of these findings, henceforth, the Model 4 results are presented and discussed in the following section. Interestingly, though, the sign and significance of the coefficients are common across specifications, while the magnitudes of influence are also close when comparing specifications on the same level of aggregation (M1 and M3; M2 and M4).

\section{Discussion of Results}

In this section, the main results presented in Table 2 are discussed and compared with the relevant literature. In this regard, the paucity of previous studies focusing specifically on WF drivers necessitates 
a comparison of our results with those of other papers analysing the determinants of water productivity or crop yields.

Regarding the worldwide results of Model 4 in Table 2, the WF seems to be driven more by demographic and macroeconomic considerations rather than by input structure or climatic factors. In particular, population is found to be the main factor determining WF (with an elasticity of -1.00), suggesting that rising aggregate demand (large population base) is met by lower water intensity, or the existence of economies of scale. The presence of economies of scale is also found by Roson and Damania [13] when assessing the drivers of the WF, with an elasticity of -0.74 for water intensity growth with respect to the output growth. Moreover, a positive relationship between population and crop yield is also found in the literature [20,33]. This effect has an apparent contradiction with those studies that associate larger population countries with lower development (i.e., reduced birth control) and, therefore, with lower yields [32]. However, our data, as in [20,33], have a panel structure, so changes in population refer not only to changes between countries but also over time. In this sense, many authors have argued that an increasing population over time has led to increasing demand for food and increasing land pressure (due, for example, to urbanization processes), which has necessitated significant rises in agricultural productivity [19].

Results also indicate that a $1 \%$ increase in GDP per capita leads to a reduction in the WF of $-0.42 \%$, suggesting that economic development facilitates a falling water requirement per unit of production. This result is consistent with the previous literature, where economic progress is found to have a positive impact on water productivity [22,34] and caloric yield [33,35]. Taking a broader perspective, this specific result may be attributed to several influencing factors, such as technological change, infrastructural capacity or political governance and stability.

The observed impact of macroeconomic variables on WFs gives one cause for optimism regarding future scenarios since, although population and economic growth have increased the pressure on finite water resources (see Figure 1), they have also gone hand-in-hand with the reduced water requirements per unit of production (i.e., improved productivity). Notwithstanding, the key point here is how far into the future such a trend will continue. A cursory examination of the literature reveals that opinion is split, with some commentators arguing that actual yields are approximating maximum permissible levels [32], while others postulate continued room for improvement [19,26].

Regarding the structural input factors, and in line with a priori expectations, capital, labour and fertiliser yield are found to decrease the WF, indicating that higher input productivity leads to lower water use per dollar of production, most plausibly through an increment in crop yields. Specifically, a $1 \%$ increase in capital, labour and fertiliser yield reduces the WF by $-0.35 \%,-0.40 \%$, and $-0.07 \%$, respectively. The nexus between input productivity and yield or water productivity is perfectly consistent with previous studies in the empirical literature, among others, [19-21,25,32,35].

Of particular note is the fact that the use of fertiliser has been shown to be one of the main drivers of crop yield over the last century $[21,24,25,32,34]$. However, although we obtain a statistically significant elasticity, our results indicate that the impact of fertiliser yield is less pronounced than that of other variables. The reason may be that, although fertiliser productivity and intensity notably increased at the end of the 19th century and early 20th century, in recent decades this trend has plateaued [20,21].

Climatic conditions also appear to influence the WF. Specifically, a $1 \%$ increase in temperature reduces the WF by $-0.016 \%$. The sign of this effect in the previous literature is diverse, with some scholars obtaining a positive relationship [20] and others a negative one [21]. This divergence may be attributed to the geographical scope of the studies, since an increase in temperature may increase yield in some areas and decrease it in others, depending on the latitude and the irrigation application [36,37]. One should bear in mind that a higher temperature usually implies a higher solar radiation, which facilitates crop growth. In contrast, a higher temperature can also lead to greater soil aridity and, therefore, to lower yields. However, these arid areas may have a greater incentive to make a more efficient use of water and, therefore, to reduce the WF. In any case, a result that is common to most 
previous studies is that the impact of climatic variables (such as the temperature) is usually weaker than the effect of the economic and technological factors as, for example, in $[19,21,26]$.

Finally, the estimated coefficient of the time trend is positive and statistically significant, although its magnitude is very limited. The positive sign of this coefficient may be somewhat surprising, as one would expect that the technical progress experienced over time would be accompanied by a falling WF, as was previously obtained in the related literature $[20,35]$. A possible explanation for this result is the longer choice of time period for our panel dataset (2002-2016), which encompassed the economic shock effects in the wake of the global economic crisis in 2008, compared with previous papers covering only up to the year 2007.

To validate this hypothesis, model 4 (M4) was re-estimated allowing the coefficients of all variables to be different between the two periods 2002-2008 $\left(\mathrm{t}_{0}\right)$ and 2009-2016 $\left(\mathrm{t}_{1}\right)$, as follows:

$$
\begin{gathered}
\ln \mathrm{WF}_{\mathrm{it}}=\alpha+\delta_{0} \mathrm{t}_{0}+\delta_{1} \mathrm{t}_{1}+\beta_{1} \ln \mathrm{GDPpc}_{\mathrm{it}_{0}}+\beta_{2} \ln \mathrm{GDPpc}_{\mathrm{it}_{1}}+\beta_{3} \ln \mathrm{POP}_{\mathrm{it}_{0}}+\beta_{4} \ln \mathrm{POP}_{\mathrm{it}_{1}}+ \\
\beta_{5} \ln \mathrm{KYIELD}_{\mathrm{it}_{0}}+\beta_{6} \ln \mathrm{KYIELD}_{\mathrm{it}_{1}}+\beta_{7} \ln \mathrm{LYIELD}_{\mathrm{it}_{0}}+\beta_{8} \ln \mathrm{LYIELD}_{\mathrm{it}_{1}}+\beta_{9} \ln \mathrm{FYIELD}_{\mathrm{it}_{0}}+ \\
\beta_{10} \ln \mathrm{FYIELD}_{\mathrm{it}_{1}}+\beta_{11} \ln \mathrm{TEMP}_{\mathrm{it}_{0}}+\beta_{12} \ln \mathrm{TEMP}_{\mathrm{it} 1}+\mathrm{u}_{\mathrm{it}}
\end{gathered}
$$

After estimating Equation (3), the null hypothesis of the equal coefficients of each variable in both periods is tested. The results are shown in Table 3, highlighting a clear change in the estimated trend

\begin{tabular}{|c|c|c|}
\hline Variables & $2002-2008$ & 2009-2016 \\
\hline Constant & \multicolumn{2}{|c|}{$\begin{array}{c}24.570^{* * *} \\
(0.6028)\end{array}$} \\
\hline Trend & $\begin{array}{l}-0.013 * * \\
(0.0055)\end{array}$ & $\begin{array}{l}0.016^{* * *} \\
(0.0014)\end{array}$ \\
\hline $\ln$ GDPpc & $\begin{array}{c}-0.409 * * * \\
(0.0250)\end{array}$ & $\begin{array}{c}-0.456^{* * *} \\
(0.0263)\end{array}$ \\
\hline $\ln \mathrm{POP}$ & $\begin{array}{c}-0.999 * * * \\
(0.0308)\end{array}$ & $\begin{array}{c}-1.002 * * * \\
(0.0310)\end{array}$ \\
\hline ln KYIELD & $\begin{array}{c}-0.337 * * * \\
(0.0091)\end{array}$ & $\begin{array}{c}-0.342^{* * *} \\
(0.0089)\end{array}$ \\
\hline ln LYIELD & $\begin{array}{c}-0.425^{* * *} \\
(0.0101)\end{array}$ & $\begin{array}{c}-0.389 * * * \\
(0.0108)\end{array}$ \\
\hline ln FYIELD & $\begin{array}{c}-0.067^{* * *} \\
(0.0037)\end{array}$ & $\begin{array}{c}-0.094^{* * *} \\
(0.0040)\end{array}$ \\
\hline $\ln$ TEMP & $\begin{array}{c}-0.017^{* * * *} \\
(0.0013)\end{array}$ & $\begin{array}{c}-0.016 \text { *** } \\
(0.0014)\end{array}$ \\
\hline Time fixed effects & \multicolumn{2}{|c|}{ YES } \\
\hline No. Observations & \multirow{2}{*}{\multicolumn{2}{|c|}{$\begin{array}{c}80,976 \\
5791\end{array}$}} \\
\hline No. Groups & & \\
\hline R-squared & \multicolumn{2}{|c|}{0.84} \\
\hline $\mathrm{H}_{0}: \delta_{0}=\delta_{1}$ & \multicolumn{2}{|c|}{$33.88^{* * *}$} \\
\hline $\mathrm{H}_{0}: \beta_{1}=\beta_{2}$ & \multicolumn{2}{|c|}{$78.22^{* * *}$} \\
\hline $\mathrm{H}_{0}: \beta_{3}=\beta_{4}$ & \multicolumn{2}{|c|}{$7.22 * * *$} \\
\hline $\mathrm{H}_{0}: \beta_{5}=\beta_{6}$ & \multicolumn{2}{|c|}{2.40} \\
\hline $\mathrm{H}_{0}: \beta_{7}=\beta_{8}$ & \multicolumn{2}{|c|}{$144.16^{* * *}$} \\
\hline $\mathrm{H}_{0}: \beta_{9}=\beta_{10}$ & \multicolumn{2}{|c|}{$196.15^{* * *}$} \\
\hline $\mathrm{H}_{0}: \beta_{11}=\beta_{12}$ & \multicolumn{2}{|c|}{0.46} \\
\hline $\begin{array}{c}\mathrm{H}_{0}: \delta_{0}=\delta_{1} ; \beta_{1}=\beta_{2} ; \beta_{3}=\beta_{4} ; \\
\beta_{5}=\beta_{6} ; \beta_{7}=\beta_{8} ; \beta_{9}=\beta_{10} ; \beta_{11}=\beta_{12}\end{array}$ & \multicolumn{2}{|c|}{$48.14^{* * *}$} \\
\hline
\end{tabular}
before and after 2008 .

Table 3. Estimated results of model M4 before and after the year 2008.

Note: robust standard errors in parentheses. ${ }^{* * *} p<0.01,{ }^{* *} p<0.05$. GDPpc refers to Gross Domestic Product per capita; POP is population; TEMP refers to the temperature change; and KYIELD, LYIELD and FYIELD is the capital, labour and fertilizer yield, respectively. 
For the period 2002-2008, the coefficient of the time trend is negative, whereas after 2008, the trend is positive. This result substantiates our hypothesis, suggesting that the possible technological progress experienced during the period 2002-2008 that led to a reducing WF has truncated since 2008. In this regard, international organizations point at several impacts of financial and economic crisis on the agricultural sector, such as the strong investment contraction, the drastic drop in domestic and international demand, or the increase in oil and other commodity prices [38]. For the other variables, the expected sign of the estimated coefficients remains stable over time, although its magnitude is statistically different (except for the temperature change and the capital yield variables), as can be seen in the lower panel of Table 3. Moreover, testing the null that the coefficients of all variables are equal in both periods, we find evidence of the existence of a global change before and after 2008 that jointly affects all the variables of the model.

WF drivers may change not only over time, but also between regions. To examine spatial variations in the drivers, Model 4 was re-estimated by geographical regions and estimated results are presented in Table 4. Most of the reported elasticities maintain the sign and the level of significance with respect to the worldwide results of Table 2, although the effects have a different intensity in the different regions. However, there are important regional differences in the effect exerted by the GDP per capita and the temperature on the WF, and in the estimated time trend coefficient.

Table 4. Estimation results of model M4 by geographical regions.

\begin{tabular}{|c|c|c|c|c|c|c|}
\hline Variables & EAP & ECA & LAC & MENA & SA & SSA \\
\hline \multirow[t]{2}{*}{ Constant } & $23.215^{* * *}$ & $33.320 * * *$ & $47.315^{* * *}$ & $36.165^{* * *}$ & $16.077^{* * *}$ & $11.829^{* * *}$ \\
\hline & $(0.7384)$ & (1.0101) & $(2.6656)$ & (1.3088) & (1.2927) & $(1.2410)$ \\
\hline \multirow[t]{2}{*}{ Trend } & $0.006^{* * *}$ & $0.013^{* * *}$ & $0.030 * * *$ & $0.029 * * *$ & $-0.018^{* * *}$ & $0.006^{* * *}$ \\
\hline & $(0.0008)$ & $(0.0004)$ & $(0.0022)$ & $(0.0017)$ & $(0.0018)$ & $(0.0022)$ \\
\hline \multirow[t]{2}{*}{$\ln$ GDPpc } & $-0.098^{* * *}$ & $-0.413^{* * *}$ & $-1.076^{* * *}$ & $-1.048^{* * *}$ & $0.488^{* * *}$ & 0.061 \\
\hline & $(0.0314)$ & $(0.0300)$ & $(0.0549)$ & $(0.0558)$ & $(0.0251)$ & $(0.0386)$ \\
\hline \multirow[t]{2}{*}{$\ln \mathrm{POP}$} & $-0.997 * * *$ & $-1.535^{* * *}$ & $-2.187^{* * *}$ & $-1.460 * * *$ & $-0.670^{* * *}$ & $-0.360 * * *$ \\
\hline & $(0.0468)$ & $(0.0592)$ & $(0.1527)$ & $(0.0615)$ & $(0.0646)$ & $(0.0726)$ \\
\hline \multirow[t]{2}{*}{ ln KYIELD } & $-0.290 * * *$ & $-0.295^{* * *}$ & $-0.510^{* * *}$ & $-0.432 * * *$ & $-0.199^{* * *}$ & $-0.122 * * *$ \\
\hline & $(0.0138)$ & $(0.0102)$ & $(0.0185)$ & $(0.0227)$ & $(0.0065)$ & $(0.0117)$ \\
\hline \multirow[t]{2}{*}{ ln LYIELD } & $-0.507 * * *$ & $-0.470 * * *$ & $-0.107^{* * *}$ & $-0.314^{* * *}$ & $-0.802 * * *$ & $-0.660 * * *$ \\
\hline & $(0.0145)$ & $(0.0112)$ & $(0.0116)$ & $(0.0137)$ & $(0.0070)$ & $(0.0254)$ \\
\hline \multirow[t]{2}{*}{ ln FYIELD } & $-0.139 * * *$ & $-0.137^{* * *}$ & $-0.164^{* * *}$ & $-0.074 * * *$ & $0.029 * * *$ & $-0.023 * * *$ \\
\hline & $(0.0081)$ & $(0.0058)$ & $(0.0103)$ & $(0.0066)$ & $(0.0024)$ & $(0.0026)$ \\
\hline \multirow[t]{2}{*}{ ln TEMP } & $0.009 * * *$ & $-0.019^{* * *}$ & $-0.010^{* * *}$ & $0.034^{* * *}$ & $0.039 * * *$ & $-0.041 * * *$ \\
\hline & $(0.0013)$ & $(0.0010)$ & $(0.0014)$ & $(0.0048)$ & $(0.0015)$ & $(0.0035)$ \\
\hline Time fixed effects & YES & YES & YES & YES & YES & YES \\
\hline No. Observations & 8584 & 32,681 & 14,142 & 8096 & 4360 & 11,028 \\
\hline No. Groups & 685 & 2283 & 1009 & 557 & 291 & 825 \\
\hline R-squared & 0.93 & 0.90 & 0.79 & 0.83 & 0.98 & 0.82 \\
\hline $\begin{array}{l}\text { Note: robust star } \\
\text { POP is populatio } \\
\text { labour and fertili } \\
\text { Table } 1 \text {. North An } \\
\text { be representative }\end{array}$ & NA) regi & heses. * & $\begin{array}{l}.01 . \text { GDI } \\
\text { hange; a } \\
\text { ding full } \\
\text { since it o }\end{array}$ & rs to $\mathrm{Gr}$ & estic $\mathrm{Pr}$ & $\begin{array}{l}\text { per capita; } \\
\text { he capital, } \\
\text { eported in } \\
\text { ts may not }\end{array}$ \\
\hline
\end{tabular}

In particular, the elasticity with respect to GDP per capita is negative in ECA (Europe and Central Asia), LAC (Latin America and Caribbean), MENA (Middle East and North Africa) and EAP (East Asia and Pacific) countries (although in the latter the effect is almost negligible), but positive in SA (South Asia) and SSA (Sub-Saharan Africa) countries. This result seems to indicate that the (positive or negative) effect of GDP per capita on the WF may be conditioned by the stage of development in each region. Figure 3 shows that low income regions have a positive elasticity with respect to the GDP per capita, while medium and high income regions exhibit a negative elasticity. Therefore, in countries with a low degree of economic development (such as SSA and some countries of Asia), economic 
progress may not lead to improved efficiency in the use of water resources, but rather is accompanied by increasing water intensity.

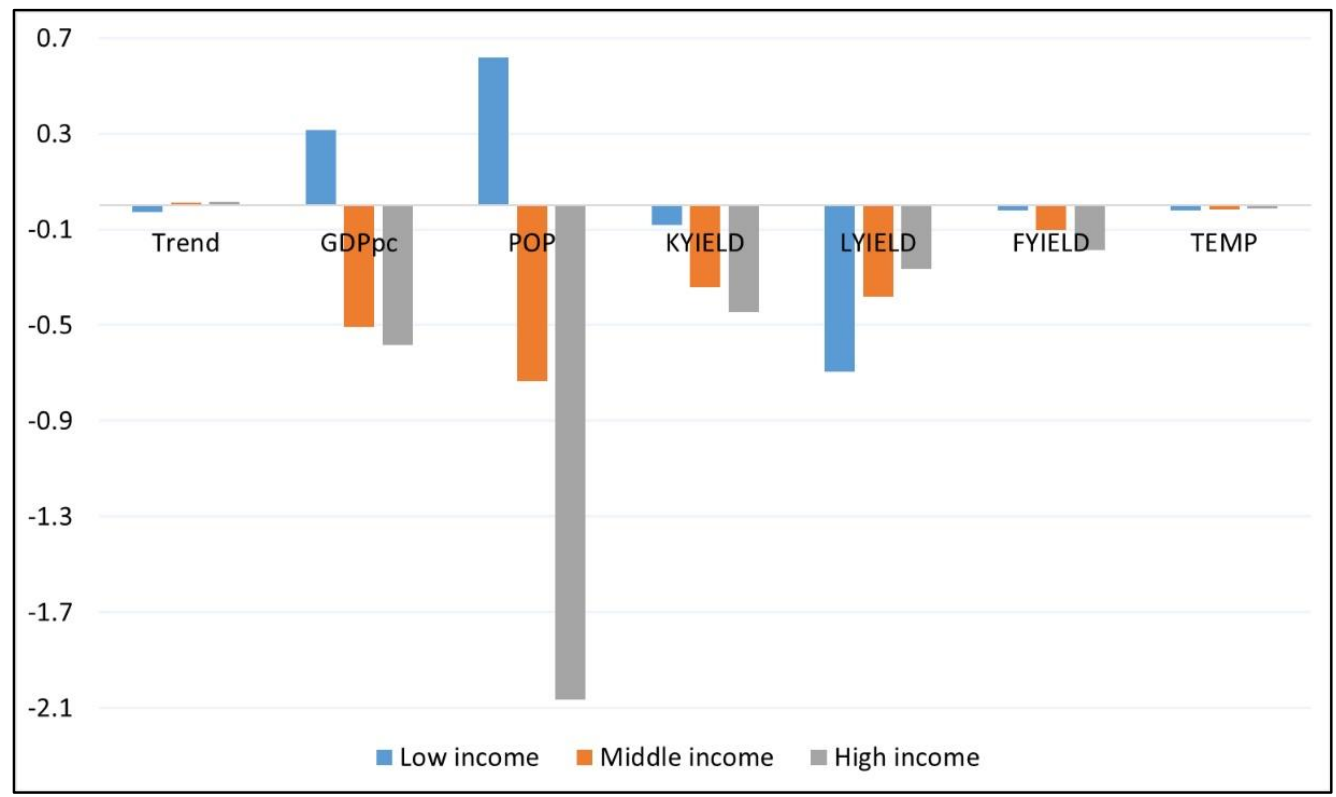

Figure 3. Elasticities of determinants on the WF by income groups. Elasticities are estimated with specification M4, segmented by income groups. GDPpc refers to Gross Domestic Product per capita; POP is population; TEMP refers to the temperature change; and KYIELD, LYIELD and FYIELD is the capital, labour and fertilizer yield, respectively.

Regarding the time trend, all regions exhibit a positive sign of the estimated coefficient, with the exception of SA. The reason for this may be the different way in which the 2008 financial crisis has affected the different regions of the world. Indeed, it has been observed that whilst this crisis affected SA through the slowdown in trade, Asia was largely spared from the shock of the credit market crisis that plagued the United States and the European Union [39]. In a similar way, conducting a segmented estimation by income groups, Figure 3 shows that low income countries exhibit a negative coefficient for the time trend, whereas developed economies have a positive coefficient, reflecting the strong impact that the financial crisis had in the latter countries.

Figure 3 also shows that the effect of population on the WF varies significantly by income group, indicating the existence of diseconomies of scale in the least developed countries, and economies of scale in the middle and high income countries. Moreover, the elasticities with respect to the capital and fertiliser yields are greater the higher the income level, while the effect of labour yield decreases when the income level increases. These results possibly confirm the notion that more mechanised larger scale farming practises, as is typically found in more developed countries, are strongly water-saving. Notwithstanding, this desirable outcome should not deflect attention from other negative environmental considerations arising from intensive farming techniques.

Regarding the effect of the temperature on the WF, Table 4 shows that this elasticity is negative in ECA, LAC and SSA, but positive in EAP, MENA, and SA. This regional divergence is consistent with the different effects that an increase in temperature may have on crop yields and on the WF according to the latitude [37]. Thus, in regions along the 30th-40th parallel north, which are those with the greatest water scarcity, an additional increase in temperature leads to a greater crop WF. On the contrary, in other regions with less water scarcity, a higher temperature leads to a reduction in the WF. This seems to indicate that, in regions with a greater water scarcity, an increase in temperature can imply a disproportionate level of water stress and aridity and crop yield reductions. On the contrary, in more temperate regions with relatively less water scarcity, a higher temperature can lead, at least 
in the period under consideration, to better climatic conditions that may facilitate longer growing seasons and marginal improvements in yields. In Europe, this result is consistent with the findings of the European Environmental Agency [40].

\section{Conclusions}

The water footprint (WF) is a key metric for assessing the relative efficiency of freshwater withdrawals across regions and through time. Notwithstanding, the dynamics of WF drivers, although recognised, remain empirically under researched, especially at the global scale. An improved understanding of the relative influence of said mechanisms on the WF across regions and through time, particularly in vulnerable areas, is essential in weighing up alternate policy prescriptions promoting sustainable growth, responsible input usage or emissions reductions for relieving water stress. The resulting resilience to water stress not only has important implications for food security, economic development and climatic adaptation, but is also instrumental in reducing the humanitarian costs arising from conflicts over scarce resources.

This paper evaluates the drivers of agricultural crop WF over time and space, with a particular emphasis on demographic and economic factors. The results indicate that demographic and macroeconomic development exert a greater influence on the WF than different crop inputs or climatic conditions. This reinforces the importance of analysing economic factors, which have received little attention in the previous literature, but that can exert a noteworthy impact on the use and management of water resources.

Examining the geographical dimension more closely, the elasticities with respect to GDP per capita and to temperature changes have major implications for relatively poorer countries in hotter/drier conditions. On the one hand, the results suggest that, at lower levels of economic development, economic growth inflates the WF, which then subsides in the eventuality that the economy passes to the next stage of development. This observation signals the need for greater worldwide cooperation (i.e., burden sharing) and water governance and on the design of policies to promote more efficient technologies in the use of water in less developed countries, to ensure that their economic development is not achieved at the expense of increasing pressure on water resources.

On the other hand, the results suggest that an increase in temperature reduces the WF in regions with less water scarcity, but increases the WF in those with greater water scarcity problems. This highlights the need to pay special attention to those regions with less water availability and to the effects that climate change can have on the crop WF. In this regard, climate change is expected not only to increase the average temperature, but also to be accompanied by more extreme temperatures, which adversely affect crop yields [36,41]. So, policies attempting to mitigate the effects of climate change on water resources should take into account these regional patterns and how they can change over time, producing geographical displacements in crop production that can lead to important socio-economic and environmental consequences.

The results also show that time is also a key factor when assessing WF (at least in crop sectors). The conclusion to draw from this is that the assumption of zero, or steady rates of WF, change through time, particularly in foresight studies, is at best, rather simplistic and, at worst, erroneous. This finding clearly motivates the need for further study on the possible pattern of WF changes over time. Moreover, further research should be channelled into a greater understanding of the lower achievable bounds of the WF through the limits to water efficiency. With uncertainty surrounding the continued benefits of genetic modification and increasing land pressures, these 'yield gaps' [42], and the consequent WF implications, are challenging to quantify.

This research is a first step toward better understanding the dynamics of the WF, although, as with all research endeavours, one must be mindful of its limitations and the need for further research. Firstly, in better understanding the idiosyncrasies of the WF through space, a higher level of spatial granularity for specific regions would be welcome-for example, to understand whether the patterns of the drivers can be truly generalised to individual countries within a region. Secondly, to shed light 
on the future evolution of the WF, at least with a view to understanding whether the WF drivers return to the pre-crisis trend. Thirdly, there is a need to delve more deeply into the differences between diverse types of crops with varied water requirements and different proportions of irrigated (blue water) and rainfed (green water) land.

Author Contributions: P.G.-d.-R. was involved in all stages of the research paper and led the data collection, econometric estimation and writing of the paper. G.P. conceptualised the research idea as well helping with the writing of the paper. H.F.-P., and A.I.S. provided vital technical input into the methodological approach, the data construction and processing, the formal analysis, the econometric estimation, and the writing of the paper. All authors have read and agreed to the published version of the manuscript.

Funding: This project has received funding from the European Union's Horizon 2020 research and innovation programme under grant agreement No 773297 (Monitoring the Bioeconomy-BioMonitor); from the Instituto Nacional de Investigación y Tecnología Agraria y Alimentaria (INIA) (RTA2017-00046-00-00), co-funded by FEDER “Operational Program Smart-Growth" 2014-2020, for the project "Bioeconomía 2030: Un análisis cuantitativo de las perspectivas a medio plazo en España"; and from the Department of Science, Technology and Universities of the Aragonese Government and the European Regional Development Fund under the consolidated reference research group S01_17R “Economía agroalimentaria y de los recursos naturales".

Conflicts of Interest: The authors declare no conflict of interest.

\section{References}

1. Allen, C.; Metternicht, G.; Wiedmann, T. National pathways to the sustainable development goals (SDGs): A comparative review of scenario modelling tools. Environ. Sci. Policy 2016, 66, 199-207. [CrossRef]

2. UN. Resolution adopted by the general assembly on 25 September 2015. A/res/70/1, seventieth session. United Nations 2015, Agenda items 15 and 116. Available online: https://www.un.org/en/development/desa/ population/migration/generalassembly/docs/globalcompact/A_RES_70_1_E.pdf (accessed on 2 March 2020).

3. UN Environment. Global Environment Outlook-GEO-6: Summary for Policymakers; Cambridge University Press: Nairobi, Kenya, 2019. [CrossRef]

4. Hoekstra, A.Y. (Ed.) Virtual Water Trade: Proceedings of the International Expert Meeting on Virtual Water Trade, Delft, The Netherlands, 12-13 December 2002; Value of Water Research Report Series No. 12; UNESCO-IHE: Delft, The Netherlands, 2003.

5. Hoekstra, A.Y.; Chapagain, A.K.; Aldaya, M.M.; Mekonnen, M.M. The Water Footprint Assessment Manual_Setting the Global Standard; Earthscan: London, UK, 2011.

6. Soligno, I.; Malik, A.; Lenzen, M. Socioeconomic Drivers of Global Blue Water Use. Water Resour. Res. 2019, 55, 5650-5664. [CrossRef]

7. D' Odorico, P.; Carr, J.; Laio, F.; Ridolfi, L. Spatial organization and drivers of the virtual water trade: A community-structure analysis. Environ. Res. Lett. 2012, 7, 034007. [CrossRef]

8. Fracasso, A. A gravity model of virtual water trade. Ecol. Econ. 2014, 108, 215-228. [CrossRef]

9. Tamea, S.; Carr, J.A.; Laio, F.; Ridolfi, L. Drivers of the virtual water trade. Water Resour. Res. 2014, 50, 17-28. [CrossRef]

10. Duarte, R.; Pinilla, V.; Serrano, A. The effect of globalisation on water consumption: A case study of the Spanish virtual water trade, 1849-1935. Ecol. Econ. 2014, 100, 96-105. [CrossRef]

11. Duarte, R.; Pinilla, V.; Serrano, A. Understanding agricultural virtual water flows in the world from an economic perspective: A long term study. Ecol. Indic. 2016, 61, 980-990. [CrossRef]

12. Orlowsky, B.; Hoekstra, A.Y.; Gudmundsson, L.; Seneviratne, S. Today's virtual water consumption and trade under future water scarcity. Environ. Res. Lett. 2014, 9, 074007. [CrossRef]

13. Roson, R.; Damania, R. The macroeconomic impact of future water scarcity. An assessment of alternative scenarios. J. Policy Modeling 2017, 39, 1141-1162. [CrossRef]

14. Vanham, D.; Hoekstra, A.Y.; Bidoglio, G. Potential water saving through changes in European diets. Environ. Int. 2013, 61, 45-56. [CrossRef]

15. Vanham, D.; del Pozo, S.; Pekcan, A.G.; Keinan-Boker, L.; Trichopoulou, A.; Gawlik, B.M. Water consumption related to different diets in Mediterranean cities. Sci. Total Environ. 2016, 573, 96-105. [CrossRef] [PubMed]

16. Mekonnen, M.M.; Fulton, J. The effect of diet changes and food loss reduction in reducing the water footprint of an average American. Water Int. 2018, 43, 860-870. [CrossRef] 
17. Ercin, A.E.; Hoekstra, A.Y. Water footprint scenarios for 2050: A global analysis. Environ. Int. 2014, 64, 71-82. [CrossRef] [PubMed]

18. Hejazi, M.; Edmonds, J.; Clarke, L.; Kyle, P.; Davies, E.; Chaturvedi, V.; Wise, M.; Patel, P.; Eom, J.; Calvin, K.; et al. Long-term global water projections using six socioeconomic scenarios in an integrated assessment modeling framework. Technol. Forecast. Soc. Chang. 2014, 81, 205-226. [CrossRef]

19. Ewert, F.; Rounsevell, M.D.A.; Reginster, I.; Metzger, M.J.; Leemans, R. Future scenarios of European agricultural land use: I. Estimating changes in crop productivity. Agric. Ecosyst. Environ. 2005, 107, 101-116. [CrossRef]

20. Levers, C.; Butsic, V.; Verburg, P.H.; Müller, D.; Kuemmerle, T. Drivers of changes in agricultural intensity in Europe. Land Use Policy 2016, 58, 380-393. [CrossRef]

21. Li, X.; Zhang, X.; Niu, J.; Tong, L.; Kang, S.; Du, T.; Li, S.; Ding, R. Irrigation water productivity is more influenced by agronomic practice factors than by climatic factors in Hexi Corridor, Northwest China. Sci. Rep. 2016, 6, 37971. [CrossRef]

22. Long, K.; Pijanowski, B.C. Is there a relationship between water scarcity and water use efficiency in China? A national decadal assessment across spatial scales. Land Use Policy 2017, 69, 502-511. [CrossRef]

23. Kumar, M.D.; van Dam, J.C. Drivers of change in agricultural water productivity and its improvement at basin scale in developing economies. Water Int. 2013, 38, 312-325. [CrossRef]

24. Sharma, B.; Molden, D.; Cook, S. Water use efficiency in agriculture: Measurement, current situation and trends. In Managing Water and Fertilizer for Sustainable Agricultural Intensification; Drechsel, P., Heffer, P., Magen, H., Mikkelsen, R., Wichelns, D., Eds.; International Fertilizer Industry Association (IFA): Paris, France; International Water Management Institute (IWMI): Colombo, Sri Lanka; International Plant Nutrition Institute (IPNI): Peachtree Corners, GA, USA; International Potash Institute (IPI): Horgen, Switzerland, 2015; pp. 39-64.

25. Zwart, S.J.; Bastiaanssen, W.G.M. Review of measured crop water productivity values for irrigated wheat, rice, cotton and maize. Agric. Water Manag. 2004, 69, 115-133. [CrossRef]

26. Mekonnen, M.M.; Hoekstra, A.Y. The green, blue and grey water footprint of crops and derived crop products. Hydrol. Earth Syst. Sci. 2011, 15, 1577-1600. [CrossRef]

27. Tuninetti, M.; Tamea, S.; Laio, F.; Ridolfi, L. A Fast Track approach to deal with the temporal dimension of crop water footprint. Environ. Res. Lett. 2017, 12, 074010. [CrossRef]

28. Konar, M.; Hussein, Z.; Hanasaki, N.; Mauzerall, D.L.; Rodriguez-Iturbe, I. Virtual water trade flows and savings under climate change. Hydrol. Earth Syst. Sci. 2013, 17, 3219-3234. [CrossRef]

29. FAO. Faostat Database. Available online: http://www.fao.org/faostat/es/\#home (accessed on 2 March 2020).

30. Expósito, A.; Berbel, J. Drivers of Irrigation Water Productivity and Basin Closure Process: Analysis of the Guadalquivir River basin (Spain). Water Resour. Manag. 2019, 33, 1439-1450. [CrossRef]

31. World Bank. World Development Indicators. Available online: https://datacatalog.worldbank.org/dataset/ world-development-indicators (accessed on 2 March 2020).

32. Neumann, K.; Verburg, P.H.; Stehfest, E.; Müller, C. The yield gap of global grain production: A spatial analysis. Agric. Syst. 2010, 103, 316-326. [CrossRef]

33. Tilman, D.; Fargione, J.; Wolff, B.; D'Antonio, C.; Dobson, A.; Howarth, R.; Schindler, D.; Schlesinger, W.H.; Simberloff, D.; Swackhamer, D. Forecasting agriculturally driven global environmental change. Science 2001, 292, 281-284. [CrossRef]

34. Cai, X.; Molden, D.; Mainuddin, M.; Sharma, B.; Ahmad, M.D.; Karimi, P. Producing more food with less water in a changing world: Assessment of water productivity in 10 major river basins. Water Int. 2011, 36, 42-62. [CrossRef]

35. Tilman, D.; Balzer, C.; Hill, J.; Befort, B.L. Global food demand and the sustainable intensification of agriculture. Proc. Natl. Acad. Sci. USA 2011, 108, 20260-20264. [CrossRef]

36. Alcamo, J.; Dronin, N.; Endejan, M.; Golubev, G.; Kirilenko, A. A new assessment of climate change impacts on food production shortfalls and water availability in Russia. Glob. Environ. Chang. 2007, 17, 429-444. [CrossRef]

37. Kang, Y.; Khan, S.; Ma, X. Climate change impacts on crop yield, crop water productivity and food security. Prog. Nat. Sci. 2009, 19, 1665-1674. [CrossRef]

38. Lin, J.Y.; Martin, W. The financial crisis and its impacts on global agriculture. Agric. Econ. 2010, 41, $133-144$. [CrossRef] 
39. Park, D.; Ramayandi, A.; Shin, K. Why did Asian Countries fare better during the financial crisis than during the Asian Financial Crisis? In Responding to the Financial Crisis: Lessons from Asia, then, the United States and Europe Now; Rhee, C., Posen, A.S., Eds.; Asian Development Bank and Petersen Institute for International Economics: Washington, DC, USA, 2013; Chapter 4; pp. 103-139.

40. European Environment Agency. Indicator Assessment, Data and Maps: Water-Limited Crop Yields. Available online: https://www.eea.europa.eu/data-and-maps/indicators/crop-yield-variability-2/assessment (accessed on 2 March 2020).

41. Challinor, A.J.; Wheeler, T.R.; Craufurd, P.Q.; Ferro, C.A.T.; Stephenson, D.B. Adaptation of crops to climate change through genotypic responses to mean and extreme temperatures. Agric. Ecosyst. Environ. 2007, 119, 190-204. [CrossRef]

42. Van Ittersum, M.K.; Cassman, K.G. Yield gap analysis-Rationale, methods and applications-introduction to the special issue. Field Crop. Res. 2013, 143, 1-3. [CrossRef]

(C) 2020 by the authors. Licensee MDPI, Basel, Switzerland. This article is an open access article distributed under the terms and conditions of the Creative Commons Attribution (CC BY) license (http://creativecommons.org/licenses/by/4.0/). 